\title{
Genetic differentiation between the Old and New types of Serbian Tsigai sheep
}

\author{
Mirjana ĆINKULOV ${ }^{1}$, Miika TAPIO ${ }^{2}$, Mikhail OZEROV $^{2}$, \\ Tatyana KISELYOVA ${ }^{3}$, Nurbiy MARZANOV ${ }^{4}$, Ivan PIHLER ${ }^{1}$, \\ Ingrid OLSAKER ${ }^{5}$, Mensur VEGARA ${ }^{6}$, Juha KANTANEN ${ }^{2 *}$ \\ ${ }^{1}$ Department of Animal Science, Faculty of Agriculture, University of Novi Sad, \\ 21000 Novi Sad, Serbia \\ ${ }^{2}$ Biotechnology and Food Research, MTT Agrifood Research Finland, \\ 31600 Jokioinen, Finland \\ ${ }^{3}$ All-Russian Research Institute of Animal Genetics and Breeding, Russian Academy \\ of Agricultural Science, 189620 St Petersburg-Pushkin, Russia \\ ${ }^{4}$ All-Russian Research Institute of Animal Husbandry, Russian Academy \\ of Agricultural Science, 142132 Dubrovitsy, Russia \\ ${ }^{5}$ Department of Basic Sciences and Aquatic Medicine, Norwegian School \\ of Veterinary Science, PO Box 8146 Dep., 0033 Oslo, Norway \\ ${ }^{6}$ Noragric, Department of International Environment and Development Studies, \\ Norwegian University of Life Sciences (UMB), P.O. Box 5003, 1432 Ås, Norway
}

(Received 23 July 2007; accepted 13 November 2007)

\begin{abstract}
Two Tsigai sheep populations exist in Serbia: the Old type, called Čokan, and the New type. It is assumed that the New type results from upgrading Tsigai sheep with exotic genetic material. We investigated genetic diversity and differentiation of these types by analysing 23 autosomal microsatellites. Tests for Hardy-Weinberg proportions, linkage equilibrium between genotypes across loci and the calculation of inbreeding coefficients were performed and the deficiency in the number of alleles within the Tsigai types was examined using a Wilcoxon sign-rank test. The New type displayed a higher level of genetic variability than the Čokan in terms of allele numbers, but the New Tsigai showed a pattern of heterozygosity deficiency. The positive $f$ value for the Čkan suggests the occurrence of inbreeding in this type. The proportion of linkage disequilibrium was below that expected by chance. Exclusion of two loci in HardyWeinberg disequilibrium did not alter our conclusions based on the entire data set i.e. the two Tsigai types are clearly differentiated and the New Tsigai type has been influenced by crossbreeding. Therefore, the Čokan Tsigai should be considered as a distinct endangered breed in the FAO classification.
\end{abstract}

microsatellite / sheep / Tsigai

*Corresponding author: juha.kantanen@mtt.fi

Article published by EDP Sciences and available at http://www.gse-journal.org or http://dx.doi.org/10.1051/gse:2008006 


\section{INTRODUCTION}

The Tsigai sheep is one of the oldest Southeast European sheep breeds, used for milk, meat and wool production and is associated with local traditions and food culture. The breed might have originated from Turkey [18] and subsequently spread to the Balkan region, Hungary, Slovakia, Czech Republic, Moldavia and Russia. Tsigai sheep arrived in the former Yugoslavia in the $18^{\text {th }}$ century [11]. During the $20^{\text {th }}$ century, both officially recorded governmental and poorly documented private sheep sectors existed in the former Yugoslavia. In Serbia, the governmental farms raised purebred Tsigai sheep, which form the core of the current Old Tsigai type, also called the Čokan. During the same period, the private sector developed a New Tsigai sheep type, which based on phenotypic similarities, could result from undocumented crossbreeding with Bergamo sheep from Italy. The Old Tsigai type has relatively homogeneous phenotypic characters while the New type shows greater variation among individuals [3]. Because of its larger body size, the New Tsigai type has become popular among farmers and increased in number while the population size of the Old Tsigai type is decreasing, with currently less than 500 breeding females [22].

In the present study, we analysed the genetic diversity and differentiation of the two Tsigai types in Serbia using 23 microsatellites. In addition, we examined their genetic differentiation in a wider context by including Finnish, Russian and Ukrainian sheep breeds in the analysis. The choice of the breeds selected for the analysis was based on demographic and geographic characteristics: Russian Tsigai is assumed to share ancestry with the Serbian Tsigai, the Carpathian Mountain Sheep and Sokolsk originate from geographically proximate regions and Finnsheep and Romanov are examples of breeds that have been bred pure and kept isolated from other breeds. If the Čokan sheep shows clear differentiation from the New Tsigai type and other sheep breeds, it should be given an FAO status of an endangered-maintained breed [21]. Previously, the genetic divergence between closely related populations belonging to the same breed, was studied in Merino, Sarda Sheep and Finnsheep [6, 14, 23], in Holstein-Friesian cattle [8] and in the Lipizzan Horse [1]. These molecular studies showed that genetic profiles of farm animal breeds do not necessarily reflect the assumed demographic history and that breeds can show a strong fragmented within-breed structure as a result of genetic differentiation between the subpopulations of the breed. 


\section{MATERIALS AND METHODS}

\subsection{Animals, DNA extraction and microsatellite analysis}

Blood samples were randomly collected from 50 Tsigai sheep of each type. Two sheep breeds from Ukraine (Carpathian Mountain and Sokolsk), two from Russia (Russian Tsigai and Romanov) and one from Finland (Finnsheep), described by Tapio et al. [25, 26], were included in the analysis of breed relationships.

DNA was extracted from the whole blood using a standard phenol/chloroform extraction protocol [20]. In total 100 Serbian Tsigai sheep were genotyped for 23 microsatellite markers (BM0757, BM1314, BM1818, BM4621, BM6506, BM6526, BM8125, CSSM31, MAF214, MAF36, MAF48, MAF65, McM527, OarCP20, OarCP34, OarCP38, OarFCB11, OarFCB128, OarFCB304, OarFCB48, OarHH47, OarHH64 and OarVH72). Individual microsatellites were genotyped by PCR amplification in a total volume of $10 \mu \mathrm{L}$ containing $10 \mathrm{ng}$ DNA template, $1 \mathrm{X}$ PCR buffer with 5\% DMSO, $1.5 \mathrm{mM}$ $\mathrm{MgCl}_{2}$ or $3.25 \mathrm{mM} \mathrm{MgCl}{ }_{2}$ (for BM1818 and CSSM31), 1 unit of Taq DNA polymerase, $0.2 \mathrm{mM}$ of each dNTP and 2 pmol of each primer, one of which was labelled with fluorescent dye. Amplification was performed using a touchdown protocol: initial denaturation at $94{ }^{\circ} \mathrm{C}, 5 \mathrm{~min}, 4$ rounds of 3 cycles at $94{ }^{\circ} \mathrm{C}, 45 \mathrm{~s}$ and $63{ }^{\circ} \mathrm{C}, 60^{\circ} \mathrm{C}, 57^{\circ} \mathrm{C}$ and $54^{\circ} \mathrm{C}$ respectively for $1 \mathrm{~min}$, followed by 23 to 30 cycles of $94{ }^{\circ} \mathrm{C}, 45 \mathrm{~s}, 52^{\circ} \mathrm{C}, 1 \mathrm{~min}$ and a final extension at $72{ }^{\circ} \mathrm{C}$ for $4 \mathrm{~min}$. The allele sizes were scored according to the TAMRA 500 size standard on an ABI prism 377 sequencer (Applied Biosystems, Foster City, CA, USA). Samples from Nordic standard animals were included in all gel-runs allowing adjustment of all allele sizes to the agreed sizes of the North-SheD reference samples ([25], NorthSheD project www.lbhi.is/northshed).

\subsection{Statistical analysis}

Within-population genetic variation was quantified by calculating the mean number of alleles per locus, mean observed and mean expected heterozygosities using POPGENE v1.21 [27].

Deviations from Hardy-Weinberg equilibrium (HWE) were tested using the exact test implemented in GENEPOP v.3.1 [17]. In HWE tests, a MCMC method was applied to compute unbiased estimates of the exact probabilities. The length of the chain was set at 100000 iterations. Weir and Cockerham's [28] within population fixation index $f$ (FIS) was calculated using FSTAT v2.9.1 [7]. The significance of $f$ was determined by 
1000 permutations. Linkage disequilibrium between pairs of microsatellite loci was tested using the exact test in GENEPOP v3.1.

The occurrence of recent genetic bottlenecks was tested using BOTTLENECK [16]. In the testing, the ratio of allele numbers and expected heterozygosities was compared to the ratio expected under the mutation-drift equilibrium [9]. The equilibrium heterozygosities were obtained from 1000 iterations, assuming that the allelic states of microsatellites change according to the Stepwise Mutation Model (SMM) and Two-phased model of mutations (TPM) [4]. The default settings for the proportion of stepwise and larger mutations and variance of allele size change were used [16]. After simulation, the significances of deviations were tested with the Wilcoxon sign-rank test.

The magnitude of genetic differentiation between the two Tsigai sheep types was calculated with Weir and Cockerham's theta $(\theta)$ [28] using FSTAT v.2.9.1 [7].

In order to estimate the likelihood of an individual's multilocus genotype occurring in a given population, we computed the statistical certainty of assignment for each individual by using the Bayesian based assignment test in the GENECLASS v.1.0 program [5]. The simulation options (1000 simulated individuals per population and threshold value to reject population was $1 \%$ ) and the direct assignment with the 'leave one out' procedure were applied.

The breed relationship analysis of the two Serbian Tsigai types, Russian Tsigai, Carpathian Mountain sheep, Sokolsk, Romanov and Finnsheep was based on the $\mathrm{D}_{\mathrm{A}}$ distance [10]

$$
\mathrm{D}_{\mathrm{A}}=1-1 / r \sum_{j}^{r} \sum_{i}^{m_{j}} \sqrt{ } \mathrm{X}_{i j} \mathrm{Y}_{i j}
$$

where $\mathrm{X}_{i j}$ and $\mathrm{Y}_{i j}$ refer to the frequencies of the $i^{\text {th }}$ allele at the $j^{\text {th }}$ locus in populations $\mathrm{X}$ and $\mathrm{Y}$, respectively, $m_{j}$ is the number of alleles at the $j^{\text {th }}$ locus, and $r$ is the number of analysed loci. A set of 15 microsatellites available for all breeds (refer to [25]) was used for the calculation. The analysis was done using DISPAN [12]. The robustness of the Neighbour-joining tree [19] was tested by bootstrapping (5000 replicates over loci) and presented graphically using TREEVIEW v1.6 6. [13].

\section{RESULTS}

\subsection{Genetic variation and population structure}

Genotype data are available upon request from M.Ć. All microsatellite loci were polymorphic in both Tsigai sheep types. A total of 205 alleles were found. 
Table I. Within-population genetic diversity and inbreeding estimates in the Old and New Serbian Tsigai types. In addition, probabilities obtained from the Wilcoxon signrank test in the BOTTLENECK analysis are presented.

\begin{tabular}{lcccc}
\hline Tsigai type & $\boldsymbol{n}$ & MNA & H $_{\text {OBS }}$ & H $_{\text {EXP }}$ \\
\hline Old & 50 & 6.7 & 0.64 & 0.69 \\
New & 50 & 7.5 & 0.66 & 0.70 \\
\hline \multicolumn{4}{c}{$\boldsymbol{f}[\mathbf{9 5 \%}$ CI for $\boldsymbol{f}]$} \\
\hline Old & 50 & $0.086[0.033,0.148]$ \\
New & 50 & $0.072[0.007,0.150]$ \\
Old & 50 & \multicolumn{2}{c}{$0.073[0.02,0.136]$} \\
New & 50 & \multicolumn{2}{c}{$0.040[-0.11,0.094]$} \\
\hline \multicolumn{4}{c}{ Wilcoxon's sign-rank test } \\
& \multicolumn{4}{c}{ P-value } \\
\hline Old & 50 & 0.1234 & P-value \\
New & 50 & 0.0002 & 0.6001 \\
Old & 50 & 0.2367 & 0.0022 \\
New & 50 & 0.0007 & 0.0057 \\
\hline
\end{tabular}

Genetic diversity

Inbreeding

all 23 markers

Inbreeding

21 markers*

\section{Bottleneck testing}

all 23 markers

Bottleneck testing 21 markers*

$n=$ Number of individuals included in the analysis.

MNA $=$ Mean number of alleles per microsatellite locus.

$\mathrm{H}_{\mathrm{OBS}}=$ Mean observed heterozygosity.

$\mathrm{H}_{\mathrm{EXP}}=$ Mean expected heterozygosity.

$f=$ Within-population inbreeding estimate.

95\% CI for $f=95 \%$ confidence intervals for the estimate of $f$.

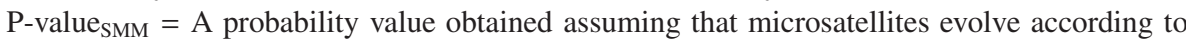
the stepwise mutation model.

P-value $\mathrm{TPM}_{\mathrm{TPM}}=\mathrm{A}$ probability value obtained assuming that microsatellites evolve according to the two-phased mutation model.

* Estimates are based on 21 markers, the MAF214 and OarHH64 were excluded from the analysis.

The mean allele number per locus was 8.7, ranging from 5 (BM0757, BM6506 and OarCP34) to 12 (BM1314 and BM1818). Two loci (MAF214 and OarHH64) showed significant deviations $(\mathrm{P}<0.001$, Bonferroni correction applied) from HWE in both Tsigai populations due to the excess of homozygotes.

Within the Tsigai sheep the mean allelic number per locus was higher in the New type (7.5) than in the Old type (6.7) (Tab. I). Forty-one percent (85/205) of the alleles were not shared between the two Tsigai types. Thirty-three alleles were specific for the Old Tsigai, while 52 alleles were observed only in the New Tsigai. The mean observed and expected heterozygosities in the Old and New Tsigai types are given in Table I. 
The exact test for non-random association of genotypes across loci gave 23 significant values $(\mathrm{P}<0.05)$ from 506 comparisons $(10$ in the New and 13 in the Old Tsigai type). The total number of significantly small P-values was therefore less than would be expected by chance alone for 506 independent tests.

Within-population inbreeding estimates $(f)$ in both Tsigai types were positive and significantly different from zero $(\mathrm{P}<0.001)$, indicating that parents were more related than expected under random mating (Tab. I). Excluding the markers MAF214 and OarHH64, that displayed a statistically significant excess of homozygotes, both Tsigai types still showed positive $f$-estimates, but only the estimate for the Old type deviated significantly from zero (Tab. I).

Performing the Wilcoxon sign-rank BOTTLENECK test [4] assuming that the microsatellite alleles evolved according to SMM or TPM models did not indicate loss of alleles in the Old Tsigai (Tab. I). However, the New Tsigai displayed a pattern of heterozygosity deficiency, i.e. there were too many alleles compared to the level of gene diversity. Excluding the two anomalous markers did not alter the test conclusions.

\subsection{Genetic differentiation}

The between-population inbreeding index, theta $(\theta)$, was $0.110(\mathrm{P}<0.05$, significantly different from zero), indicating that $11 \%$ of the total genetic variation was explained by differences between the Tsigai types, while the remaining $89 \%$ was due to differences among individuals.

Genetic differentiation at the individual level was investigated with a Bayesian approach implemented in the GENECLASS v.1.0 program. Animals were assigned to the correct Old or New Tsigai populations with success rates of $90 \%$ and $88 \%$, respectively. The output of the calculation is presented graphically in Figure 1. The plotting of log-likelihood values obtained for all samples clearly indicates distinct grouping of animals into the Old Tsigai and New Tsigai types. In addition, greater uniformity among the sampled genotypes of the Old Tsigai was suggested by the average log-likelihood value (25.43), while for the New type the corresponding mean suggested greater heterogeneity (43.72).

We calculated $\mathrm{D}_{\mathrm{A}}$ genetic distances among the two Serbian Tsigai types and five European sheep breeds (Finnsheep, Romanov, Russian Tsigai, Carpathian Mountain and Sokolsk). The genetic distance between the two Tsigai types $\left(D_{A}=0.2234\right)$ was greater than the average distances among the five other sheep breeds $\left(D_{A}=0.1730\right)$ studied here $(T a b . ~ I I)$. However, one of the three 


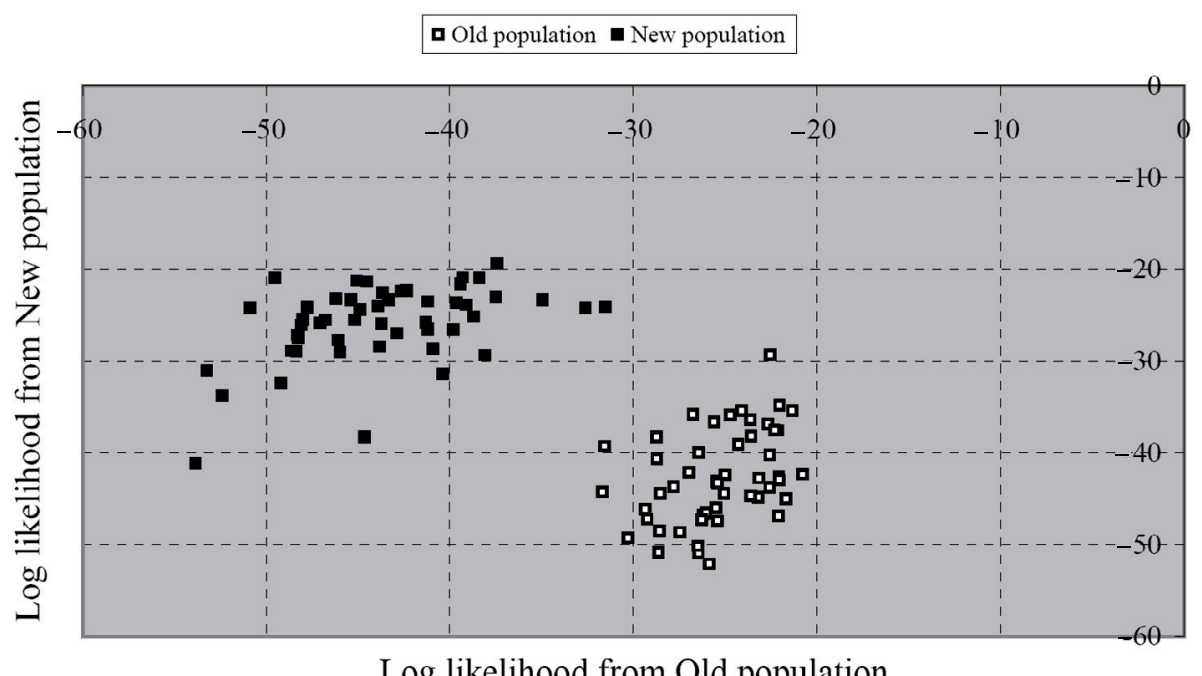

Figure 1. A plot of log-likelihood values obtained in the assignment test for all individuals. Two clearly distinct groups (the Old Tsigai and the New Tsigai) can be identified indicating their genetic differentiation.

Table II. Matrix of $\mathrm{D}_{\mathrm{A}}$ distances among the seven sheep breed and populations.

\begin{tabular}{lccccccc}
\hline & 1 & 2 & 3 & 4 & 5 & 6 & 7 \\
\hline 1. Old Tsigai & - & & & & & & \\
2. New Tsigai & 0.2234 & - & & & & & \\
3. Romanov & 0.2922 & 0.3192 & - & & & & \\
4. Carpathian Mountain & 0.1713 & 0.2006 & 0.2328 & - & & & \\
5. Sokolsk & 0.1928 & 0.2039 & 0.2409 & 0.1058 & - & & \\
6. Russian Tsigai & 0.1848 & 0.1894 & 0.1955 & 0.0881 & 0.0996 & - & \\
7. Finnsheep & 0.2411 & 0.2672 & 0.2079 & 0.1937 & 0.1951 & 0.1709 & - \\
\hline
\end{tabular}

well-supported clusters in the phylogenetic tree (Fig. 2) consisted of the two Tsigai types. The other two were a northern short-tailed group, consisting of the Finnsheep and Romanov, and interestingly a southern Russian/Ukrainian cluster, containing the Russian Tsigai and the two studied Ukrainian breeds, the Carpathian Mountain sheep and Sokolsk.

\section{DISCUSSION}

The Tsigai sheep occurs in many southeast European countries and also in southern Russia, and consists of phenotypically and geographically different 


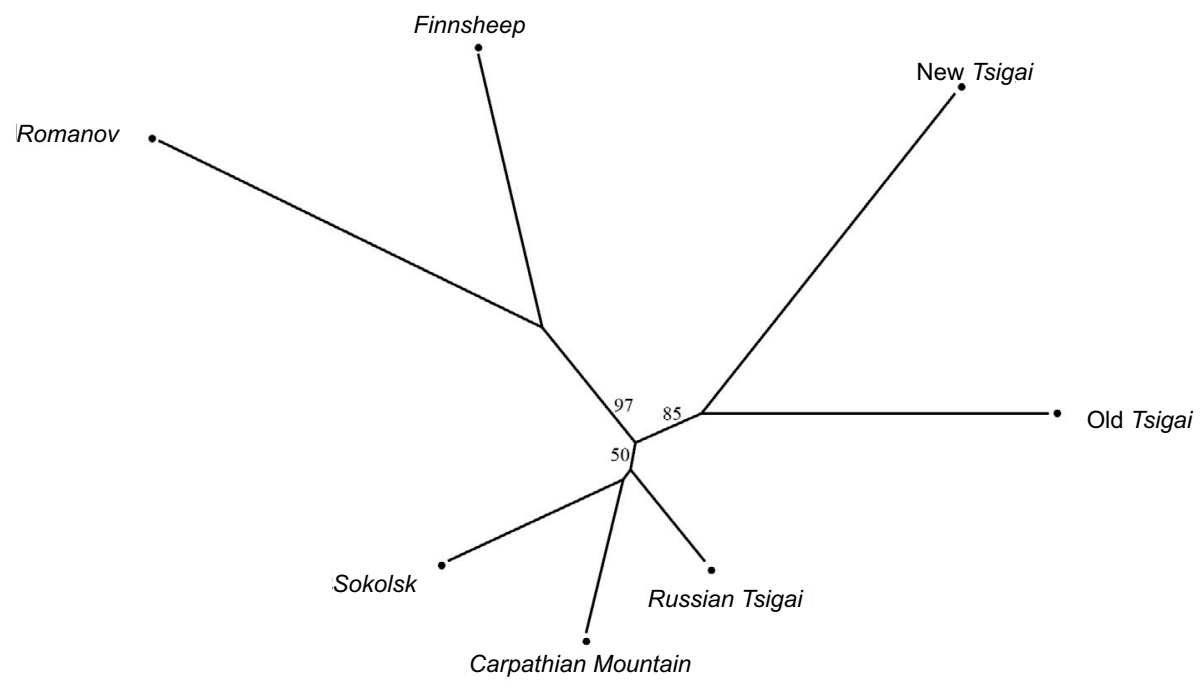

Figure 2. Unrooted neighbour-joining tree constructed from $\mathrm{D}_{\mathrm{A}}$ distances showing the relationships between seven sheep breeds and populations. Numbers at the nodes represent the percentage of group occurrence in 1000 bootstrap replicates.

varieties used for meat, milk and wool production. Two different types of Tsigai sheep exist in Serbia: the Old type, called Čokan, and the New type. Our microsatellite data revealed a substantial genetic differentiation between these Serbian Tsigai types. According to the results of F-statistics [28], 11\% of the total genetic variation in the Serbian Tsigai sheep can be explained by type differences. This significant differentiation exceeds that detected among six Spanish sheep breeds (6\%, eight markers in common with our study) [2], among seven Baltic breeds (8.8\%, 21 common markers) [24] and even that presented for 57 European and Middle Eastern sheep breeds (approximately on average 6\%, eight common markers) [15]. Moreover, the Bayesian assignment of animals to the source populations supported the clear-cut differentiation between the two Tsigai types (Fig. 1). The degree of differentiation between the two Tsigai types was further quantified using $\mathrm{D}_{\mathrm{A}}$ genetic distance and a set of reference breeds. The analysis indicated that the two types are as different, if not more different, as an average breed pair. In previous microsatellite-based studies, a similar kind of high genetic divergence among populations within the same breed from different geographical locations has been recorded $[6,8,14]$, reflecting the important contribution of genetic drift to the differentiation of domestic animal populations. 
In the New type, 19 of the 23 microsatellite loci showed too many alleles compared to the level of gene diversity, which is significantly more frequent than that supposed by stochastic effects alone. The most obvious explanation for this observation and the higher within-population diversity found in the New type is that the population has been influenced by gene flow from an exotic breed (or breeds), introducing foreign rare alleles, or in the extreme case making the original Tsigai alleles rare [9]. The crossbreeding may also explain the greater phenotypic diversity of the New type than that displayed by the Old type [3]. The census size of the Old Tsigai type has decreased dramatically, but the present bottleneck test did not indicate loss of alleles in the population due to a severe reduction of effective population size [9]. However, the positive $f$ value indicates the occurrence of inbreeding in the Old type.

The genetic divergence of the two Serbian Tsigai populations was also investigated in a wider context by performing an analysis of breed relationships including Russian Tsigai, two Ukrainian long-tailed sheep breeds and two northern European short-tailed breeds (Fig. 2). The branching pattern of the tree was robust as indicated by high bootstrap values and suggests that the Old and the New Serbian Tsigai types constitute a group of their own. The clear genetic divergence between the Serbian Tsigai types is apparent and is evidenced by the length of the branches. The Russian Tsigai tends to group with the Ukrainian breeds with short branch lengths, indicating that the gene pool of the Russian Tsigai may have been influenced by crossbreeding. Our microsatellite data indicate that the Čokan has not been upgraded with exotic genetic material, making the population an important genetic reservoir in the conservation of genetic resources of native southeast European Tsigai sheep. We recommend that an FAO status of endangered sheep breed be given to the Čkan Tsigai sheep.

\section{ACKNOWLEDGEMENTS}

The authors wish to express their gratitude to owners of Tsigai sheep for their help and collaboration in the sampling of the present research material. We acknowledge the financial support from the Norwegian Royal Ministry of Foreign Affairs and the Research Council of Norway. We are thankful for Ole Albert Gutterstud on technical assistance in microsatellite typing and Dr. Meng-Hua Li for valuable comments on an earlier draft of this manuscript. Mr Jovo Kosanovic from the Centre for Feed Technology, Norway, is acknowledged for collaboration and support. 


\section{REFERENCES}

[1] Achmann R., Curik I., Dovc P., Kavar T., Bodo I., Habe F., Marti E., Sölkner J., Brem G., Microsatellite diversity, population subdivision and gene flow in the Lipizzan horse, Anim. Genet. 35 (2004) 285-292.

[2] Álvarez I., Royo L.J., Fernández I., Gutiérrez J.P., Gómez E., Goyache F., Genetic relationships and admixture among sheep breeds from Northern Spain assessed using microsatellites, J. Anim. Sci. 82 (2004) 2246-2252.

[3] Ćinkulov M., Krajinović M., Pihler I., Phenotypic differences between two types of Tsigai breed of sheep, Lucrai stiintifice Zootehnie si Biotehnologii, vol. XXXVI, Romenia, 2003.

[4] Cornuet J.M., Luikart G., Description and power analysis of two tests for detecting recent population bottlenecks from allele frequency data, Genetics 144 (1996) 2001-2014.

[5] Cornuet J.-M., Piry S., Luikart G., Estoup A., Solignac M., New methods employing multilocus genotypes to select or exclude populations as origins of individuals, Genetics 153 (1999) 1989-2000.

[6] Diez-Tascón C., Littlejohn R.P., Almeida P.A.R., Crawford A.M., Genetic variation within the Merino sheep breed: analysis of closely related populations using microsatellites, Anim. Genet. 31 (2000) 243-251.

[7] Goudet J., FSTAT version 1.2: a computer program to calculate F-statistics, J. Heredity 86 (1995) 485-486.

[8] Hanslik S., Harr B., Brem G., Schlötterer C., Microsatellite analysis reveals substantial genetic differentiation between contemporary New World and Old World Holstein Friesian populations, Anim. Genet. 31 (2000) 31-38.

[9] Luikart G., Cornuet J.M., Empirical evaluation of test for identifying recently bottlenecked populations from allele frequency data, Conserv. Biol. 12 (1998) 228-237.

[10] Nei M., Tajima F., Tateno Y., Accuracy of estimated phylogenetic trees from molecular data, J. Mol. Evol. 19 (1983) 153-170.

[11] Ogrizek A., Ovčarstvo, Poljoprivredni nakladni zavod, Zagreb, Croatia, 1948.

[12] Ota T., DISPAN: Genetic distance and phylogenic analysis, The Pensylvannia State University, PA, USA, 1993.

[13] Page R.D.M., TREEVIEW: An application to display phylogenetic trees on personal computers, Comput. Appl. Biosci. 12 (1996) 357-358.

[14] Pariset L., Savarese M.C., Cappuccio I., Valentini A., Use of microsatellites for genetic variation and inbreeding analysis in Sarda sheep flocks of central Italy, J. Anim. Breed. Genet. 120 (2003) 425-432.

[15] Peter C., Bruford M., Perez T., Dalamitra S., Hewitt G., Erhardt G., ECONOGENE Consortium, Genetic diversity and subdivision of 57 European and Middle-Eastern sheep breeds, Anim. Genet. 38 (2007) 37-44.

[16] Piry S., Luikart G., Cornuet J.M., Bottleneck: A computer program for detecting recent reduction in the effective population size using allele frequency data, J. Hered. 90 (1999) 502-503.

[17] Raymond M., Rousset F., GENEPOP version 1.2: population genetics software for exact tests and ecumeniscism, J. Hered. 86 (1995) 248-249. 
[18] Ryder M.L., Sheep and man, London: Duckworth, 1983.

[19] Saitou N., Nei M., The neighbour-joining method: a new method for reconstructing phylogenetic trees, Mol. Biol. Evol. 4 (1987) 406-425.

[20] Sambrook J., Fritsch E.F., Maniatis T., Molecular cloning: A laboratory manual, 2nd edn., Cold Spring Harbor Laboratory Press, New York, USA, 1989.

[21] Scherf B.D., World watch list of domestic animal diversity, 3rd edn., U.N. Food and Agriculture Organization, Rome, 2000.

[22] Stojanović S., Đorđević-Milošević S., Autochtonous breeds of domestic animals in Serbia and Montenegro, Belgrade, 2003.

[23] Tapio M., Miceikiene I., Vilkki J., Kantanen J., Comparison of microsatellite and blood protein diversity in sheep: inconsistencies in fragmented breeds, Mol. Ecol. 12 (2003) 2045-2056.

[24] Tapio I., Tapio M., Grislis Z., Holm L.-E., Jeppsson S., Kantanen J., Miceikiene I., Olsaker I., Viinalass H., Eythorsdottir E., Unfolding of population structure in Baltic sheep breeds using microsatellite analysis, Hered. 94 (2005a) 448-457.

[25] Tapio M., Tapio I., Grislis Z., Holm L.E., Jeppsson S., Kantanen J., Miceikiene I., Olsaker I., Viinalass H., Eythorsdottir E., Native breeds demonstrate high contributions to the molecular variation in the northern European sheep, Mol. Ecol. 14 (2005b) 3951-3963.

[26] Tapio M., Marzanov N., Ozerov M., Ćinkulov M., Gonzarenko G., Kiselyova T., Murawski M., Viinalass H., Kantanen J., Sheep mitochondrial DNA variations in European, Caucasian and Central Asian areas, Mol. Biol. Evol. 23 (2006) 1776-1783.

[27] Yeah F.C., Yang R., Boyle T., Popgene version 1.01. Quick User Guide, available at http://www.ualberta.ca/ fyeh/popgene.pdf

[28] Weir B.C., Cockerham C.C., Estimating F-statistics for the analysis of population structure, Evolution 38 (1984) 1358-1370. 